\title{
Associations as cues in recognition memory
}

\author{
JOEL S. FREUND, KITTY SANDERS, RONNY J. BELL, and BEVERLY JENNINGS \\ University of Arkansas, Fayetteville, Arkansas 72701
}

\begin{abstract}
The present experiment tested the possibility that the improved recognition performance which results from instructing subjects to produce associations to study items is an artifact of the distributed practice (MP-DP) effect. Four groups of 30 subjects were presented a list of 50 high-frequency words with instructions to: (a) repeat each word aloud twice (REP); (b) pronounce each word, produce an association, and repeat the word (PAR); (c) pronounce each word and produce an associate to it (PA): (d) no particular instructions (Control). Two other groups were presented the study words with an additional word in parentheses next to each study item. This additional word was either a high associate (condition FAR) or an unrelated word (condition FNR). Both groups pronounced the study item, the parenthesized word, and then repeated the study item. All subjects were then given a two-alternative, forced-choice recognition test. The results indicated that instructions to produce associations facilitated recognition performance and that this facilitation was not an artifact of the MP-DP effect. Further, having subjects actively produce an association was more beneficial than having them read one which was provided.
\end{abstract}

In 1970, Underwood and Freund combined the frequency theory of Ekstrand, Wallace, and Underwood (1966) and notions about the production of implicit associative responses (IARs) to account for the empirical observation that recognition is poorer for high-frequency than for low-frequency words (e.g., Gorman, 1971). The same rationale used by Underwood and Freund inevitably leads to the prediction that any manipulation which increases the likelihood of IARs being elicited during study would lead to poorer recognition. Thus, if only a frequency attribute is considered, the theory must predict that recognition of high-frequency words under a set to repeat study items will be better under a set to produce associations.

However, specific tests of this prediction (Zechmeister \& Gude, 1974; Hall \& Pierce, Note 1; Light \& Selhorst, Note 2) have found that subjects instructed to produce associations to items at the time of study showed better recognition than subjects instructed to repeat study items or subjects given neutral instructions.

It has been suggested (Underwood, 1972, 1974; Zechmeister \& Gude, 1974) that subjects may be using the association produced during the study as an aid to recognition memory. While it is possible that subjects are using the associations as cues to aid their recognition, the improved performance may also be an artifact of what has been called the distributed practice or MP-DP effect.

To show how the MP-DP effect could account for the observed results, it is necessary to examine the procedure subjects might use in studying the list of words.

Typically, subjects are instructed that they should produce an association to each word in the list but that

This article is based on research reported at the 46th Annua! meeting of the Midwestern Psychological Association, Chicago, May 1974. they will be required to remember only the study items. It is reasonable to assume that the subject says the word aloud (or to himself), produces an association, and then repeats the word. This would result in two repetitions of the study item, separated by a different word (the association) or distributed practice on the study item. Subjects instructed to repeat each word several times would be engaged in massed practice. Since previous research (Underwood, 1969) has shown that the apparent frequency of MP words is less than that of DP words, one might expect, according to frequency theory, that subjects instructed to produce associations would show better recognition. The present experiment attempted to test this explanation by forcing subjects to use various repetition strategies.

\section{METHOD}

\section{Design}

Six conditions were determined by the combination of instructions and type of study list. In four of the conditions, subjects were presented with a list of single words for study and were asked to use various strategies. Subjects in the control condition were not given any specific instructions. Subjects in the repetition (REP) condition were asked to pronounce each word aloud twice, thus providing massed repetition on each word. The subjects in the remaining single-word conditions were asked to produce an associate to each word as it was presented. The subjects in the PAR condition were told to pronounce the presented word, produce an associate, and then repeat the original word. The subjects in Condition PA were told to pronounce the presented word and then produce an associate. They were not told to repeat the study item.

Subjects in the remaining two conditions were presented the same list as the other subjects. However, a second word was presented in parentheses beside each study item. For subjects in Condition FAR, the parenthesized word was a high associate of the study item. For subjects in Condition FNR, the parenthesized word was not related to the study item. Both groups were told to pronounce the study item, then the parenthesized word, and then repeat the study word. 
Lists

The study items were 50 stimulus words from the Palermo and Jenkins (1964) norms. The associates used in Condition FAR were high associates to each study item. The neutral words used in the study portion of Condition FNR started with the same letter and had the same Thorndike-Lorge frequency as the associates used in Condition FAR. The distractors used on the test were also matched to the associates in the same manner.

The words were presented in a random order, and the same order was used for all subjects. The recognition test list consisted of 50 pairs composed of an old word and a distractor. The pairs were typed on a sheet of paper in two columns of 25 pairs each; the order of the pairs was random. With each pair, the position of the old item was random, with the restriction that equal number of old words and distractors occur in each position (left and right).

\section{Subjects and Procedure}

The subjects were 180 University of Arkansas students serving in experiments as part of a course requirement. The subjects were assigned to the six conditions according to a block-randomization procedure.

Once seated in front of the memory drum, the subjects were read instructions appropriate to the condition to which they were assigned. They were also told that after presentation of the list their memory for the words would be tested; the exact nature of the test was not explained. Subjects in the PAR, PA, FAR, and FNR conditions were instructed that the additional words they produced (or read) might help them remember the study items but that they would be tested only on the study items.

The study list was presented at a 2.5 -sec rate on a Stowe memory drum. After all 50 items were presented, the subjects were given the recognition test list and were told to circle the word in each pair which had been presented. Subjects were required to circle one word from each pair.

\section{RESULTS}

The mean number of errors per condition and the results of a Newman-Keuls analysis are shown in Table 1. Several results are obvious from examination of the table. First, the superior performance of subjects told to produce an association was not due to the distribution of rehearsals, since subjects in Condition FNR made more errors than subjects in either the PA or PAR conditions. Second, the act of producing an association played an important part in correct recognition since subjects forced to pronounce an associate which had been provided (FAR) made more errors than subjects who produced their own associations (PAR, PA). Third,

Table 1

Mean Number of Errors for Each Condition and the Results of a Neuman-Keuls Analysis

\begin{tabular}{|c|c|c|c|c|c|}
\hline \multicolumn{6}{|c|}{ Condition } \\
\hline PAR & PA & REP & FAR & CONT & FNR \\
\hline .77 & 1.17 & 4.20 & 5.43 & 9.30 & 10.67 \\
\hline
\end{tabular}

Note-A line under any two means indicates they did not differ $(p>.05)$. Any means not underlined by the same line differed from all others $(p<.05)$. distribution of repetitions seems to be no more effective than simply repeating the target item (FNR vs. REP).

Since all words used in the study list were stimulus words from Palermo and Jenkins (1964), it is possible that the facilitating effect of producing an association can be explained by the fact that the associations which the subjects produced were other target items. Thus, the frequency of these items would be enhanced, making discrimination on the basis of frequency easier. To examine this possibility, the number of times each word (or a form of it) in the study list was given as an associate was tabulated. Of the 50 target words, 27 were given as associates at least once, for a total of 137 times by the 60 subjects (PA and PAR combined). Thus, on the average, each subject produced .08 repetitions of each of the 27 target words. Although this amount of repetition does not appear to be large enough to account for the large effect of association instructions, further analyses were carried out.

If elicitation of the study words as associations caused the improvement in performance, two additional findings would be expected. First, there should be fewer errors made on the items elicited as associations than on those not elicited, and, second, there should be a negative correlation between the number of times a word was elicited as an association and the number of errors on that item.

There were 36 errors made on the 27 items which were given at least once as an association, for a mean of 1.33 errors per item; only 22 errors were made on the remaining 23 items, for a mean of .96 errors per item. This result was the opposite of what was predicted. Using only the 27 items which had been given at least once as an associate, a Pearson product-moment correlation was computed between the number of times a word was given as an association and the number of errors. The $r=-.04$. Eliminating the 15 items on which no errors were made, and performing the correlation on the remaining 12 , raised the correlation to -.28 . Although both correlations were in the predicted direction, neither was significantly greater than zero.

\section{DISCUSSION}

Three facts are apparent from the present results. First, instructions to produce an association facilitate recognition performance, replicating previous findings by Zechmeister and Gude (1974), Hall and Pierce (Note 1), and Light and Selhorst (Note 2). Second, the facilitation shown by the association-instructed group was not an artifact of the MP-DP effect. It thus appears that subjects are capable of using associations produced during study as cues in recognition tasks. Third, it seems that having subjects actively produce an association is more beneficial than having them read one that is provided. The question to be investigated now is, "How does production of associations facilitate recognition performance?"

Two possible mechanisms are proposed. First, it is possible that the act of making an association produces a memory trace or establishes an attribute for that act itself so that on the recognition test the subjects can discriminate between the two 
words by choosing the one to which an association had been made. That is, on the test, when discrimination on the basis of a frequency differential is not possible, the subject can choose the item to which he remembers having produced an association. In order to account for the difference between the active condition (producing an association) and the passive condition (reading a provided association), one could assume that the active process leaves a stronger trace than the passive one.

The second mechanism presumes that when the subject encounters a pair of items for which the frequency differential is not a viable cue, he generates an association to each item and then compares the associations, choosing the one he has seen before-the one with the highest frequency.

The research by Zechmeister and Gude (1974) indicates that subjects may be using the memory for the act of making an association as the cue rather than generating an association on the test, since instructing subjects to think of the meaning of the word produced the same facilitation as instructions to think of an association.

\section{REFERENCE NOTES}

1. Hall. J. W.. \& Pierce. J. Recognition as a fiunction of variations in me'mon -encudang instractions. Paper presented at the 13th annual meeting of the Psychonomic Suciety. St. Louis. Nusember 19:2.

2. Light. L.. d Selhorst, S. Effiects of uctivity during list study. on recognition memory for words. Paper presented at the $51 \mathrm{si}$ Annual Meeting of the Western Pstcholugical Association. San Francisco. April 1971.

\section{REFERENCES}

Ekstrand, B. R., Wallace, W. P., \& Underwood, B. J. A frequency theory of verbal-discrimination learning. Psychological Review. 1906, 73, 500-578.

GURmaN. A. M. Recognition memory for nouns as a function of abstractness and frequency. Journal of Experimental Psychology, 1961, 61. 23-29.

Palermo, D. S.. d Jenkins. J. J. Word Associution Norms. Mlinneapolis: L'niversity of Minnesota Press. 1904.

LNDERWOOD, B. J. Some correlates of item repetition in free-reciall katning. Journal of Verbal Leaming and Verbal Beharior. 1904. 8. 8.3-44.

LNDERWOOD. B. J. Recognition memory. In H. H. Kendler \& J. T. Spencer (Eds.). Essals in Neoberhaviorism: A me'morial volume to ke'nneth W. Spence. New York: Appleton-CenturyCrotts. 19-2.

UNDERW OOD, B. J. The role of association in recognition memory. Journal of Experimental Psychology, 1974. 102, 917-939.

UNDERWOOD. B. J.. \& FREUND, J. S. Word frequency and short-lerm recognition memory. American Journal of PsyChology: 1970. 83, 343-351.

ZECHMEISTER, E. B., \& GUdE, C. Instructional effects in recognition memory. Bulletin of the Psychonomic Society, 1974, 3 , 13-15. 